\title{
Atmospheric correction for satellite remotely sensed data intended for agricultural applications: impact on vegetation indices
}

\author{
D. G. Hadjimitsis ${ }^{1}$, G. Papadavid ${ }^{1,7}$, A. Agapiou ${ }^{1}$, K. Themistocleous ${ }^{1}$, M. G. Hadjimitsis ${ }^{1}$, A. Retalis ${ }^{2}$, \\ S. Michaelides ${ }^{3}$, N. Chrysoulakis ${ }^{4}$, L. Toulios ${ }^{5}$, and C. R. I. Clayton ${ }^{6}$ \\ ${ }^{1}$ Cyprus University of Technology, Department of Civil Engineering and Geomatics-Remote Sensing Laboratory, \\ Lemesos, Cyprus \\ ${ }^{2}$ Institute for Environmental Research and Sustainable Development, National Observatory of Athens, Athens, Greece \\ ${ }^{3}$ Meteorological Service, Nicosia, Cyprus \\ ${ }^{4}$ Foundation for Research and Technology - Hellas, Institute of Applied and Computational Mathematics, Heraklion, \\ Crete, Greece \\ ${ }^{5}$ National Agricultural Research Foundation, Larissa, Greece \\ ${ }^{6}$ School of Civil Engineering and the Environment, University of Southampton, Southampton, UK \\ ${ }^{7}$ Agricultural Research Institute of Cyprus, 1516, Athalassa, Nicosia, Cyprus
}

Received: 14 April 2009 - Revised: 16 December 2009 - Accepted: 18 December 2009 - Published: 14 January 2010

\begin{abstract}
Solar radiation reflected by the Earth's surface to satellite sensors is modified by its interaction with the atmosphere. The objective of applying an atmospheric correction is to determine true surface reflectance values and to retrieve physical parameters of the Earth's surface, including surface reflectance, by removing atmospheric effects from satellite images. Atmospheric correction is arguably the most important part of the pre-processing of satellite remotely sensed data. Such a correction is especially important in cases where multi-temporal images are to be compared and analyzed. For agricultural applications, in which several vegetation indices are applied for monitoring purposes, multi-temporal images are used. The integration of vegetation indices from remotely sensed images with other hydrometeorological data is widely used for monitoring natural hazards such as droughts. Indeed, the most important task is to retrieve the true values of the vegetation status from the satellite-remotely sensed data. Any omission of considering the effects of the atmosphere when vegetation indices from satellite images are used, may lead to major discrepancies in the final outcomes. This paper highlights the importance of considering atmospheric effects when vegetation indices, such as DVI, NDVI, SAVI, MSAVI and SARVI, are used (or considered) and presents the results obtained by applying the darkest-pixel atmospheric correction method on ten Landsat TM/ETM+ images of Cyprus acquired from July to December 2008. Finally, in this analysis, an attempt is
\end{abstract}

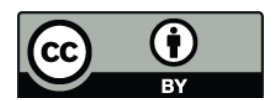

Correspondence to: D. G. Hadjimitsis (d.hadjimitsis@cut.ac.cy) made to determine evapotranspiration and to examine its dependence on the consideration of atmospheric effects when multi-temporal image data are used. It was found that, without applying any atmospheric correction, the real daily evapotranspiration was less than the one found after applying the darkest pixel atmospheric correction method.

\section{Introduction}

Radiation from the Earth's surface undergoes significant interaction with the atmosphere before it reaches the satellite sensor. This interaction with the atmosphere is stronger when the target surfaces consist of non-bright objects, such as water bodies or vegetation. This problem is especially significant when using multi-spectral satellite data for monitoring purposes, such as agricultural or land use studies. Hence, it is essential to consider the effects of the atmosphere by applying a reliable and efficient atmospheric correction during pre-processing of digital data. A considerable investigation on the effects of the atmosphere on dark targets has been already performed (Hadjimitsis et al., 2004a, b, 2008, 2009a); however, the impact of atmospheric correction on vegetation indices intended for agricultural applications has not been fully examined yet. Remote sensing data in the form of vegetation indices are widely used for agricultural and land use monitoring purposes (Hadjimitsis et al., 2009b; Liang et al., 2008). The effects of the atmosphere at spectral signatures and vegetation indices have been highlighted by Duggin and Piwinski (1984). Errors occurred by atmospheric effects influence the quality of the information extracted from remote

Published by Copernicus Publications on behalf of the European Geosciences Union. 
measurements, such as vegetation indices (Courault et al., 2003), and have been shown to increase the uncertainty up to $10 \%$, depending on the spectral band (Che and Price, 1992).

Variations in the composition and distribution of vegetation can arise in response to natural hazard (drought, wind, floods, rain erosion) and anthropic stress (industry, overgrazing, fires, land abandonment) and represents one of the main source of systematic change on local, regional, or global scale (Telesca and Lasaponara, 2006).

Regular monitoring of the vegetation status (application of derived NDVI data) along with the other parameters such as climate, soil type, and hydrology is needed to delineate the areas that are drought vulnerable. Assessment of Drought Impact on Agricultural Crops using NDVI by comparing NDVI values for humid and dry period of times can be made (Caparrini and Manzella, 2009).

Vegetation indices (VIs) have been widely used for assessing vegetation condition, cover, phenology, and processes such as evapotranspiration (ET), climate- and landuse-change detection and drought monitoring. VIs are robust satellite data products computed the same way across all pixels in time and space, regardless of surface conditions. As ratios, they can be easily cross-calibrated across sensor systems, ensuring continuity of data sets for long-term monitoring of the land surface and climate-related processes (Glenn et al., 2008).

The ability to compare pixel values this way would be useful for interpretation through the historical record and between different vegetation cover, assuming that seasonal effects are considered and data were atmospherically corrected. This paper highlights the importance of considering atmospheric effects when vegetation indices are used (or considered) and presents the results obtained by applying the darkest-pixel atmospheric correction method on ten Landsat TM/ETM+ images of Cyprus acquired from July to December 2008 .

\section{Atmospheric correction}

Any sensor that records electromagnetic radiation from the Earth's surface using visible or near-visible radiation will typically register a mixture of two kinds of energy. The value recorded at any pixel location on a remotely sensed image does not represent the true ground-leaving radiance at that point. Part of the brightness is due to the reflectance of the target of interest and the remainder is derived from the brightness of the atmosphere itself. The separation of contributions is not known a priori, so the objective of atmospheric correction is to quantify these two components; in this respect, the analysis can be based on the corrected target reflectance or radiance values. Many atmospheric correction methods have been proposed for use with multi-spectral satellite imagery (Hadjimitsis et al., 2004a). Such methods consist of image-based methods, methods that use atmospheric modeling and, finally, methods that use ground data during the satellite overpass. The Darkest Pixel (DP) atmospheric correction method, also known as the histogram minimum method (Hadjimitsis et al., 2004a), was applied to the current study. The simplest, DP correction method provided a reasonable correction, at least for cloud-free skies (Hadjimitsis et al., 2004a). The principle of the DP approach stated that most of the signal reaching a satellite sensor from a dark object was contributed by the atmosphere at visible wavelengths. Therefore, the pixels from dark targets were indicators of the amount of upwelling path radiance in this band. The atmospheric path radiance was added to the surface radiance of the dark target, thus giving the target radiance at the sensor. The surface radiance of the dark target was approximated as having zero surface radiance or reflectance (Hadjimitsis et al., 2004b).

Song et al. (2001) evaluated the effectiveness of seven absolute atmospheric correction algorithms based upon the DP principle and one relative atmospheric correction, the multitemporal normalization method by using stable features in the scene. They made this evaluation based on classification and change detection accuracies applied on a multitemporal dataset of seven Landsat-5 TM images. They found that the best overall results with respect to their impacts on image classification and change detection accuracies were achieved by using the simpler DP method, rather than the more complex atmospheric corrections that combine both atmospheric models and the dark object concept. They concluded that for applications where surface reflectance is not required, simple atmospheric correction algorithms are recommended. Hadjimitsis et al. (2004a) evaluated also the effectiveness over Landsat TM images of water treatment reservoirs, of image-based atmospheric correction algorithms and other algorithms that make use of atmospheric modeling. They found that the DP algorithm was the most efficient in the Landsat TM bands blue, green and red (1, 2 and 3, respectively). Chrysoulakis et al. (2010) compared several atmospheric correction methods for the area of Crete and investigated the effects of atmospheric correction on land cover classification and change detection. Four atmospheric correction methods were applied to a time series of ASTER images and compared. The baseline for this comparison is the spatial distribution of surface reflectance. The emitted radiance and brightness temperature as derived by ASTER Higher Level Products were used. The comparison showed that the DP method provided satisfactory results for visible, near infrared and short-wave infrared spectral areas; therefore it can be used in local level applications related to land cover and vegetation.

\section{Vegetation indices}

More than fifty different remote sensing vegetation indices have been used in the literature so far (Bannari et al., 1995). For agricultural and land use applications, the most widely 
used vegetation indices are briefly reviewed and presented below.

\subsection{Difference Vegetation Index (DVI)}

The DVI is a simple index, which is sensitive to the amount of the vegetation. DVI has the ability to distinguish the soil and vegetation but not in shaded areas. Hence, DVI does not give proper information when the reflected wavelengths are being affected due to topography, atmosphere or shadows (Akkartal et al., 2004). DVI is calculated by the following relationship:

$\mathrm{DVI}=R_{800} / R_{670}$,

where $R_{x}$ is the reflectance at the given wavelength $(\mathrm{nm})$.

\subsection{Normalized Difference Vegetation Index (NDVI)}

The NDVI is the most common and known vegetation index and has been proposed by Rouse et al. (1974). It is computed as:

$\mathrm{NDVI}=\left(R_{800}-R_{670}\right) /\left(R_{800}+R_{670}\right)$.

The sensitivity of the NDVI on atmospheric effects has generated an increasing interest in the development of new vegetation indices which are less sensitive to atmospheric effects, such as the soil-adjusted vegetation index (SAVI).

\subsection{Soil-Adjusted Vegetation Index (SAVI)}

The SAVI index has been proposed by Huete (1988) and is given by:

$\mathrm{SAVI}=(1+L) \cdot\left(R_{800}-R_{670}\right) /\left(R_{800}+R_{670}+L\right)$,

where $L$ is a canopy adjustment factor.

This simple model adequately describes the soilvegetation system. This index includes a canopy background adjustment factor $L$, which is a function of vegetation density and it requires a prior knowledge of vegetation amounts (Haboudane et al., 2004). To improve the sensitivity of SAVI to vegetation and to increase its potential to discriminating bare soil, Qi et al. (1994) proposed a modified version, namely, MSAVI (see Eq. 4). Recently, Broge and Leblanc (2000) showed that the MSAVI is the best estimator of the Leaf Area Index (LAI) in terms of sensitivity to canopy effects since it was less affected by variations in canopy parameters and soil spectral properties (Haboudane et al., 2004). MSAVI is given by:

MSAVI $=\frac{1}{2}\left[2 \cdot R_{800}+1-\sqrt{\left(2 \cdot R_{800}+1\right)^{2}-8 \cdot\left(R_{800}-R_{670}\right)}\right]$,

in order to further minimize the atmospheric effects on the NDVI index, Kaufman and Tanré (1992) proposed the Soil Atmospherically Resistant Vegetation Index (SARVI), by engaging the red-blue channel instead of the red one. The index

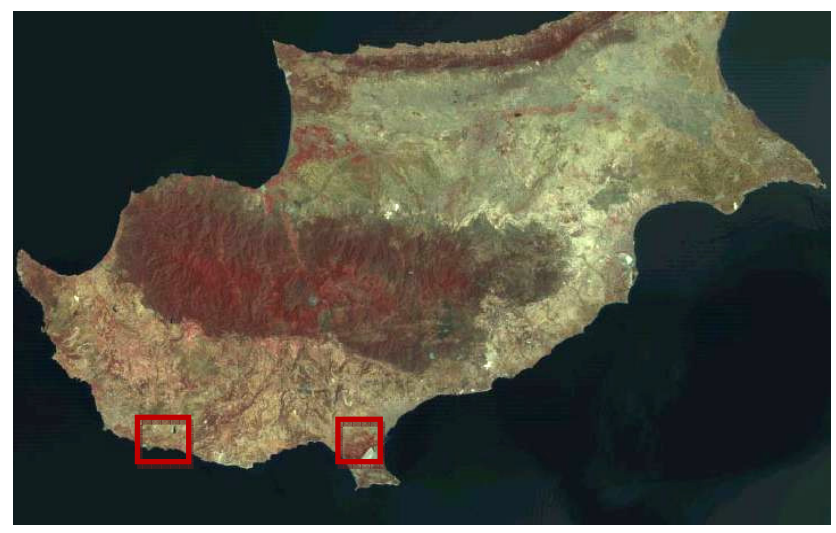

Fig. 1. Landsat TM of Cyprus. The two study areas are shown: Yeroskipou (left) and Akrotiri-Zakaki (right).

is written as:

$\mathrm{SARVI}=(1+L) \cdot\left(R_{800}-R_{\mathrm{rb}}\right) /\left(R_{800}+R_{\mathrm{rb}}+L\right)$,

where $L$ is a canopy adjustment factor and

$R_{\mathrm{rb}}=R_{\mathrm{r}}-\gamma \cdot\left(R_{\mathrm{b}}-R_{\mathrm{r}}\right)$,

where $R_{x}$ are reflectance values with prior correction for molecular scattering and ozone absorption and $\gamma$ is a constant used to stabilize the index to variations in aerosol content.

\section{Resources and Methodology}

\subsection{The study area}

Two study areas have been selected for use in this research. The first agricultural area is located at Yeroskipou area in Paphos district (the south-west area of Cyprus), consisting of Papilionaceae (Fabaceae) crop; the second area is located at Akrotiri-Zakaki area of Limassol district (the south area of Cyprus), consisting of citrus fruit trees as shown in Fig. 1.

\subsection{Satellite and field data}

Landsat TM/ETM+ images, taken at 20 and 28 July 2008, 13 and 29 August 2008, 14 and 30 September 2008, 16 October 2008, 1 and 17 November 2008, and 19 December 2008 were used. The ERDAS Imagine 9.3 software has been used for the processing of the available satellite images. Also, a GER1500 field spectro-radiometer was used to retrieve the true reflectance value of target areas consisting of $\mathrm{Pa}$ pilionaceae (Fabaceae) crops. Spectro-radiometric readings quantified the amount of atmospheric effects at different targets, thus allowing comparisons to be made with satellite retrieved reflectance. 


\subsection{The Methodology}

The overall methodology of this study is briefly presented below:

(a) Geometric correction of satellite images involves modeling the relationship between the image and ground coordinate systems. Geometric correction and georeference of each image at the World Geodetic System' 84 (WGS 84/UTM) projection system was carried out by selecting an appropriate number of well recognized ground control points (i.e. road intersections). A second order polynomial transformation was used, in an effort to keep the Root Mean Square Error (RMSE) lower than 1 pixel (see Mather, 2004).

(b) Radiometric correction of remotely sensed data normally involves the processing of digital image to reduce the influence of errors or inconsistencies (usually referred to as "noise") in image brightness values that may limit one's ability to interpret or quantitatively process and analyze digital remotely sensed images. This task is essential when handling multi-temporal images. At first, digital numbers (DN) values were converted to units of radiance by using standard calibration values. Then, the darkest pixel (DP) atmospheric correction method (also termed as histogram minimum method) was applied to the multi-series satellite images, as described in Sect. 2. A suitable dark target, such as a water dam has been selected in the area under investigation. Then an average radiance value of the dark target has been subtracted from each at-satellite radiance values in each spectral band.

(c) Calculation of Vegetation Indices and investigation of the influence of atmospheric effects by comparing the values prior and after atmospheric correction.

(d) Examination of the magnitude of atmospheric effects by comparing the satellite reflectance values and the in-situ reflectance values acquired during the satellite overpass for a target area consisting of uniform seasonal crops.

(e) The calculation of real daily evapotranspiration was used as a tool for assessing the importance of applying an atmospheric correction. The Carlson and Buffum method (Carlson and Buffum, 1989) calculates daily evapotranspiration from the daily surface energy budget using the following equation:

$\mathrm{ET}=R_{n}-B^{\prime}\left(\frac{\Delta T_{S}}{\Delta t}\right)^{n}$,

where ET is the daily evapotranspiration $\left(\mathrm{cm} \mathrm{d}^{-1}\right), R_{n}$ is the daily net radiation $\left(\mathrm{cm} \mathrm{d}^{-1}\right), \Delta T_{\mathrm{s}} / \Delta t$ is the average rate of temperature rise during the morning $\left({ }^{\circ} \mathrm{Ch}^{-1}\right) ; B$ and $n$ are constants depending on wind speed, surface roughness, vegetation, and reference height, estimated either by representative values or by charts.

\section{Results}

First, all Landsat images were undergone geometric and radiometric corrections. This section provides a detailed description of the impact of atmospheric effects on (a) the calculation of vegetation indices; (b) comparison between atsatellite reflectance and spectro-radiometric values; and (c) the calculation of real daily evapotranspiration.

\subsection{Vegetation indices}

The mean values of the vegetation indices DVI, NDVI, SAVI, MSAVI and SARVI were calculated, for Akrotiri-Zakaki area consisting of citrus fruit trees, before and after the atmospheric correction and are presented in Figs. 2-6. A mean difference of $18 \%$ for the NDVI was recorded before and after the darkest pixel method was applied. The MSAVI and especially the SARVI vegetation indices seem to be quite accurate before and after the atmospheric correction. For SARVI, the maximum difference observed was less than $4 \%$, while for MSAVI it was $12 \%$. For DVI, a mean difference of 1.8 of the index was recorded.

\subsection{Comparison between at-satellite reflectance and spectro-radiometric values}

Using the ground measurements acquired from the GER1500 field spectro-radiometer at Yeroskipou, a direct comparison was made between the satellite reflectance values and the associated ground reflectance values for Papilionaceae (Fabaceae) crop (see Table 1). From the two Landsat images for which corresponding ground measurements have been acquired during the satellite overpass, the average values of the satellite reflectance were calculated. Indeed, the percentage differences between the satellite and ground reflectance values ranged from $39 \%$ to $97 \%$. The large variations found in the satellite reflectance values, especially in TM band 1 (where the reflectance ranged from $69 \%$ to $92 \%$ ) and TM band 3 (where the reflectance ranged from $54 \%$ to $97 \%$ ), suggest that atmospheric effects were both variable and significant. Especially on the 13 August 2008 overpass, atmospheric correction showed that atmospheric such a correction was necessary (see band 1) and the algorithm was verified from the in-situ spectroradiometric measurements.

\subsection{Calculation of real daily evapotranspiration}

Using meteorological data (i.e., atmospheric pressure, maximum and minimum temperatures, wind velocity), the real daily evapotranspiration was calculated for the first case study (Yeroskipou area), using the Carslon-Buffum method (Carlson and Buffum, 1989). Actual evapotranspiration was 


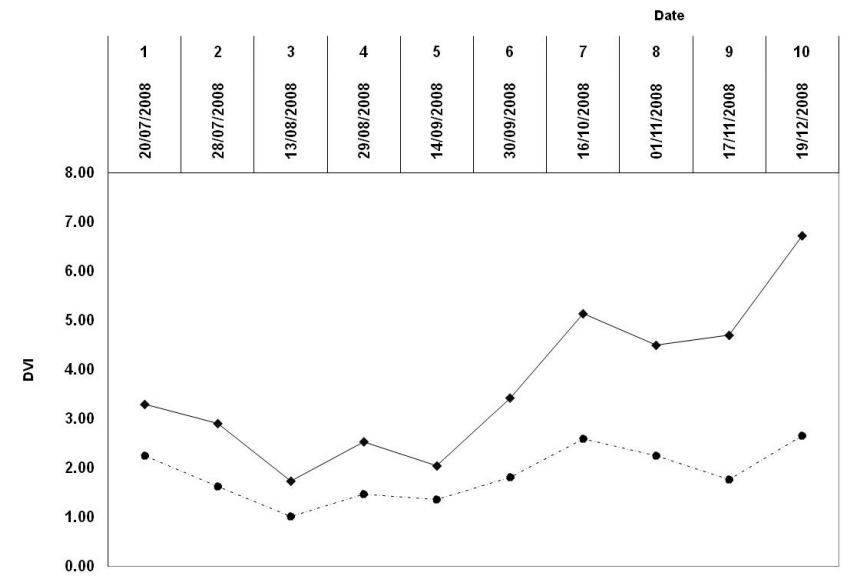

Fig. 2. DVI before (dashed line) and after (solid line) atmospheric correction.

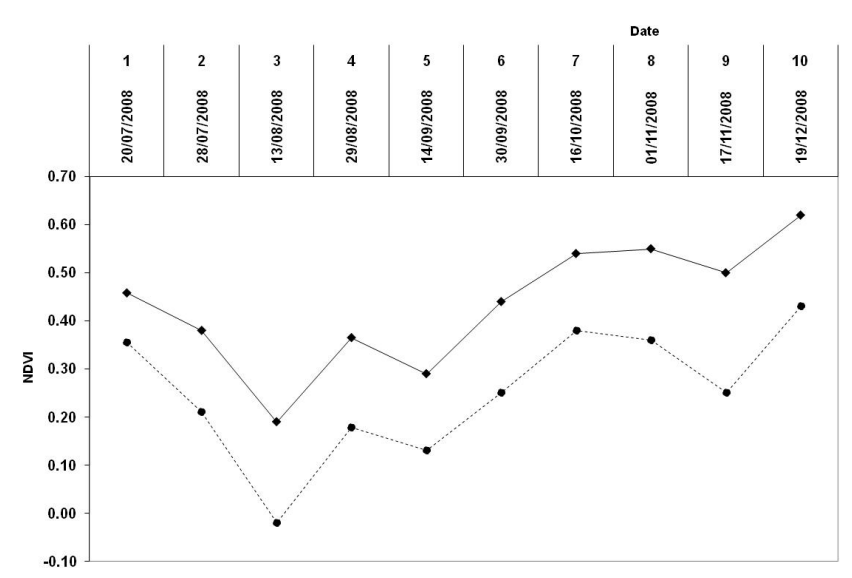

Fig. 3. NDVI before (dashed line) and after (solid line) atmospheric correction.

cross-checked with other models or algorithms, such as FAO Penman-Monteith method (FAO, 1998) and Jensen Haise method (Jensen and Haise, 1963), which show similar results for the daily evapotranspiration. It was found that the real daily evapotranspiration without performing atmospheric correction was less by $0.25-0.73 \mathrm{~mm} \mathrm{~d}^{-1}$, compared to that obtained after the application of the darkest pixel method. The results show that up to $10 \%$ less evapotranspiration can be ignored if atmospheric correction is not applied. This can be increased up to $40 \%$, when daily evapotranspiration is lower than $1.5 \mathrm{~mm} \mathrm{~d}^{-1}$.

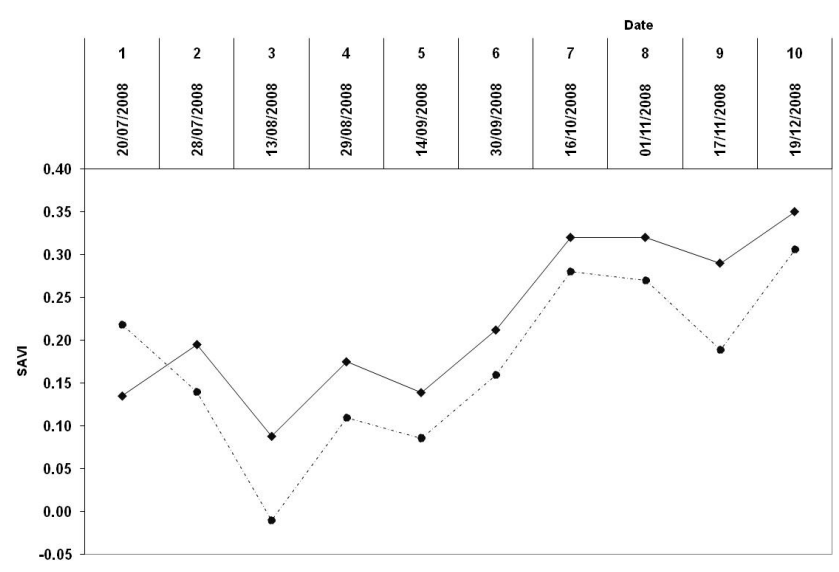

Fig. 4. SAVI before (dashed line) and after (solid line) atmospheric correction.

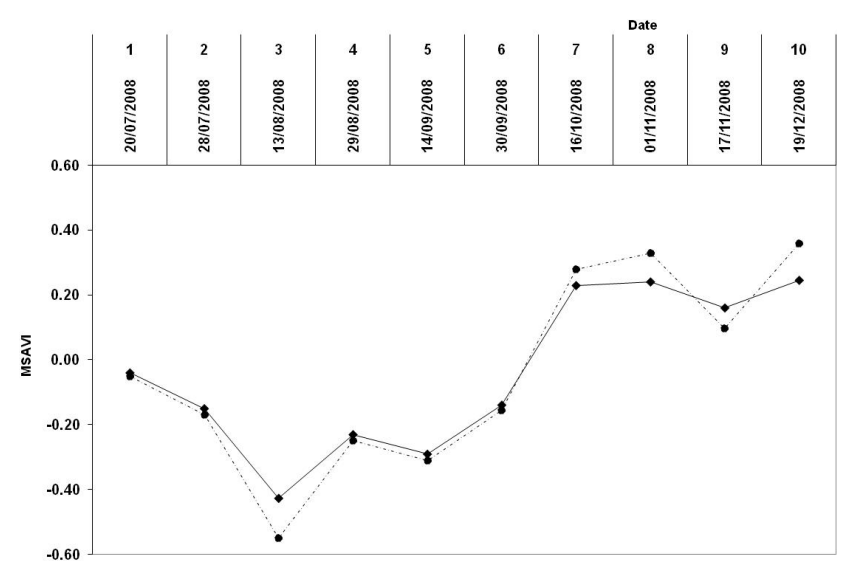

Fig. 5. MSAVI before (dashed line) and after (solid line) atmospheric correction.

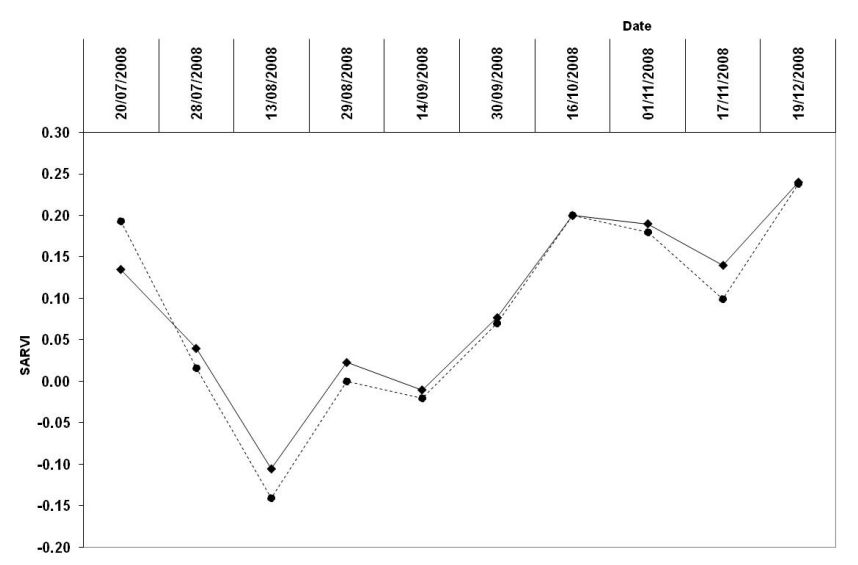

Fig. 6. SARVI before (dashed line) and after (solid line) atmospheric correction. 
Table 1. Changes of reflectance using spectro-radiometric (GER1500) measurements and from satellite data before and after atmospheric correction (AC) for 20 July 2008 and 13 August 2008 at Paphos case study.

\begin{tabular}{llcccccc}
\hline Wavelength & Band & \multicolumn{2}{c}{ Reflectance 20 July 2008 } & & \multicolumn{2}{c}{ Reflectance 13 August 2008 } \\
\cline { 3 - 5 } & & from GER1500 & before AC & after AC & from GER1500 & before AC & after AC \\
\hline $0.45-0.52 \mu \mathrm{m}$ & Blue & 0.030 & 0.096 & 0.018 & 0.010 & 0.127 & 0.010 \\
$0.52-0.60 \mu \mathrm{m}$ & Green & 0.075 & 0.090 & 0.043 & 0.030 & 0.218 & 0.080 \\
$0.63-0.69 \mu \mathrm{m}$ & Red & 0.040 & 0.087 & 0.053 & 0.005 & 0.181 & 0.079 \\
$0.76-0.90 \mu \mathrm{m}$ & Near IR & 0.400 & 0.288 & 0.262 & 0.170 & 0.309 & 0.260 \\
\hline
\end{tabular}

\section{Conclusions}

Ten Landsat TM/ETM+ images were used to test the effects of applying atmospheric correction for retrieving accurate vegetation indices and evapotranspiration. It was found that for the calculation of DVI, NDVI, SAVI and MSAVI indices the effects of the atmosphere should be considered. Only SARVI was found not to be affected from the impact of the atmosphere. Large variations in at-satellite reflectance values, especially in Landsat TM/ETM bands 1 and 3, suggest that atmospheric effects are variable and significant for crop targets. It has been shown that by not taking into account the effects of the atmosphere leads to an overestimation of the evapotranspiration from 0.25 to $0.73 \mathrm{~mm} \mathrm{~d}^{-1}$ using Landsat TM bands 1, 2, 3, and 4. A good estimation of evapotranspiration is vital for proper water management practices, improved efficiency of water use, high water productivity and efficient farming activities.

Based on the fact that NDVI has been widely used to several applications especially for agricultural monitoring purposes, the mean difference of $18 \%$ between the atmospheric and non-atmospheric corrected values has a significant meaning. Indeed, for the purposes in which NDVI is used for interpretation of growth patterns, evapotranspiration monitoring, crop management and production, to name but a few, the effects of the atmosphere must be taken into account, otherwise the retrieved outcomes will not be used for further analysis and decision making purposes.

Acknowledgements. The authors acknowledge the financial support of both the Cyprus Research Promotion Foundation, the European Union (Regional Development Funds) and the Cyprus University of Technology (internal funding and D. G. Hadjimitsis research activity funds). Thanks are also due to the Remote Sensing Laboratory of the Department of Civil Engineering and Geomatics of the Cyprus University of Technology (http://www.cut.ac.cy/).

Edited by: K. Savvidou and F. Tymvios Reviewed by: two anonymous referees

\section{References}

Akkartal, A., Türüdü, O., and Erbek, F. S.: Analyis of changes in vegetation biomass using multisensor satellite data, Proceedings of the ISPRS Congress-Youth Forum, 181-185, 2004.

Bannari, A., Morin, D., Huette, A. R., and Bonn, F.: A review of vegetation indices, Remote Sensing Reviews, 13, 95-120, 1995.

Broge, N. H. and Leblanc, E.: Comparing prediction power and stability of broadband and hyperspectral vegetation indices for estimation of green leaf area index and canopy chlorophyll density, Remote Sens. Environ., 76, 156-172, 2000.

Caparrini, F. and Manzella, F.: Hydrometeorological and vegetation indices for the drought monitoring system in Tuscany Region, Italy, Adv. Geosci., 17, 105-110, 2009, http://www.adv-geosci.net/17/105/2009/.

Carlson, T. N. and Buffum, M. J.: On estimating total daily evapotranspiration from remote surface temperature measurements, Remote Sens. Environ., 29, 197-207, 1989.

Che, N. and Price, J. C.: Survey of Radiometric calibration results and methods for visible and near infrared channels of NOAA-7, -9, and -11 AVHRRs, Remote Sens. Environ., 41, 19-27, 1992.

Chrysoulakis, N., Abrams, M., Feidas, H., and Arai, K.: Comparison of atmospheric correction methods using aster data for the area of Crete: the ATMOSAT project, Int. J. Remote Sens., in press, 2010.

Courault, D., Seguin, B., and Olioso, A.: Review to estimate Evapotranspiration from remote sensing data: some examples from the simplified relationship to the use of mesoscale atmospheric models, ICID Workshop on Remote Sensing of ET for Large Regions, 2003.

Duggin, M. J. and Piwinski, D.: Recorded radiance indices for vegetation monitoring using NOAA AVHRR data; atmospheric and other effects in multitemporal data sets, Appl. Optics, 23, 2620 2623, 1984.

FAO: Crop evapotranspiration - Guidelines for computing crop water requirements. FAO Irrigation and Drainage Papers 56, Food and Agriculture Organization of the United Nations, 1998.

Glenn, E. P., Huete, A. R., Nagler, P. L., and Nelson, S. G.: Relationship between remotely-sensed vegetation indices, canopy attributes and plant physiological processes: what vegetation indices can and cannot tell us about the landscape, Sensors, 8, 2136-2160, 2008.

Haboudane, D., Miller, J. R., Pattey, E., Zarco-Tejada, P. J., and Strachan, I. B.: Hyperspectral vegetation indices and novel algo- 
rithms for predicting green LAI of crop canopies: Modeling and validation in the context of precision agricultural, Remote Sens. Environ., 90, 337-352, 2004.

Hadjimitsis, D. G.: Description of a new method for retrieving the aerosol optical thickness from satellite remotely sensed imagery using the maximum contrast value principle and the darkest pixel approach, Transactions in GIS, 12, 633-644, 2008.

Hadjimitsis, D. G., Clayton, C. R. I., and Hope, V. S.: An assessment of the effectiveness of atmospheric correction algorithms through the remote sensing of some reservoirs, Int. J. Remote Sens., 25, 3651-3674, 2004a.

Hadjimitsis, D. G., Clayton, C. R. I., and Retalis, A.: Darkest pixel atmospheric correction algorithm: a revised procedure for environmental applications of satellite remotely sensed imagery, in: Proceedings 10th International Symposium on Remote Sensing, Proc. SPIE 5239, 464 pp, 2004b.

Hadjimitsis, D. G., Clayton, C. R. I., and Retalis, A.: The use of selected pseudo-invariant targets for the application of atmospheric correction in multi-temporal studies using satellite remotely sensed imagery, Int. J. Appl. Earth Obs., 11, 192-200, 2009a.

Hadjimitsis, D. G., Themistocleous, K., Agapiou, A., and Clayton, C.: Monitoring Archaeological Site Landscapes in Cyprus using Multi-temporal Atmospheric Corrected Image Data, International Journal of Architectural Computing, 7, 121-138, $2009 \mathrm{~b}$.

Huete, A. R.: A soil-adjusted vegetation index (SAVI), Remote Sens. Environ., 25, 295-309, 1988.

Jensen, M. E. and Haise, H. R.: Estimating evapotranspiration from solar radiation, J. Irr. Drain. Div.-ASCE, 89, 15-41, 1963.
Kaufman, Y. J. and Tanré, D.: Atmospherically resistant vegetation index (ARVI), IEEE Geosci. Remote S., 30, 261-270, 1992.

Liang, Z., Bing-fang, WU, Yue-min, Z., Ji-hua, M., and Ning, Z.: A study of fast estimation of vegetation fraction in Three Gorges emigration area by using SPOT5 imagery, in: The International Archives of the Photogrammetry, Remote Sensing and Spatial Information Sciences, Vol. XXXVII. Part B8, Beijing, 987-992, 2008.

Mather, P. M.: Computer processing of remotely-sensed images. An Introduction, Wiley, Chichester, ISBN 047198550 3, 2004.

Qi, J., Chehbouni, A., Huete, A. R., Kerr, Y. H., and Sorroshian, S.: A Modified Soil Adjusted Vegetation Index, Remote Sens. Environ., 47, 1-25, 1994.

Rouse, J. W., Haas, R. H., Schell, J. A., Deering, D. W., and Harlan, J. C.: Monitoring the vernal advancements and retrogradation (greenwave effect) of nature vegetation, NASA/GSFC Final Report, Greenbelt, 1974.

Song, C., Woodcock, C. E., Seto, K. C., Lenney, M. P., and Macomber, S. A.: Classification and change detection using Landsat TM data: when and how to correct atmospheric effects?, Remote Sens. Environ., 75, 230-244, 2001.

Telesca, L. and Lasaponara, R.: Quantifying intra-annual persistent behaviour in SPOT-VEGETATION NDVI data for Mediterranean ecosystems of southern Italy, Remote Sens. Environ., 101, 95-103, 2006. 